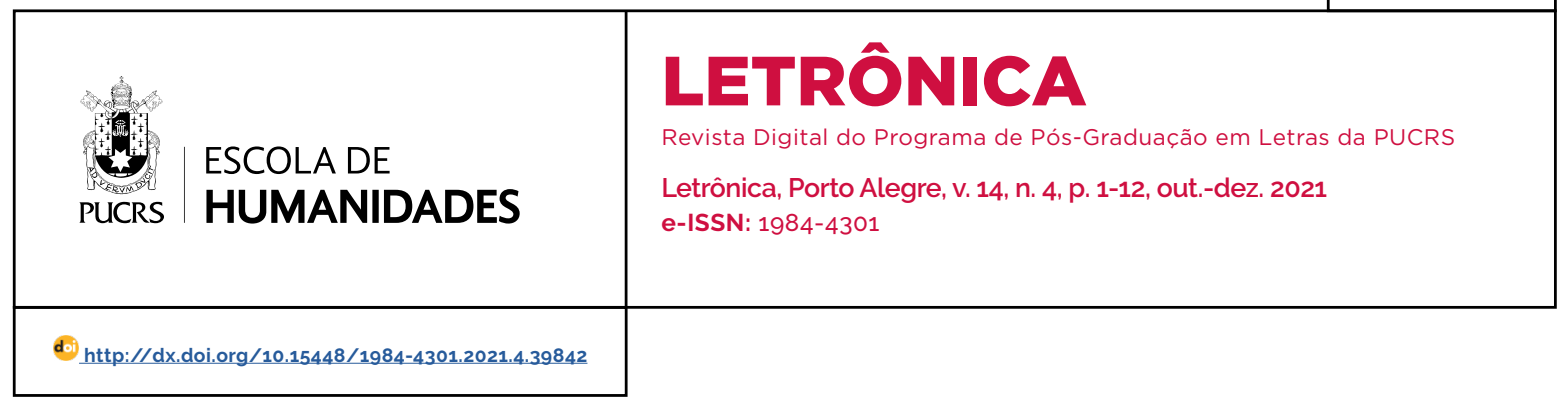

SEÇÃO: ARTIGOS

\title{
O ethos do herói voluntário e os estereótipos sobre a África no discurso humanitário
}

The ethos of the volunteer hero and stereotypes about Africa in humanitarian discourse

\section{Daiane Rodrigues de Oliveira Bitencourt ${ }^{1}$ orcid.org/0000-0002-9267-1682 daiane.unicamp@gmail.com}

Recebido em: 2 mar. 2021. Aprovado em: 25 jul. 2021. Publicado em: 27 jan. 2022.

\begin{abstract}
Resumo: Este artigo analisa o video "How to get more likes on Social Media", a fim de descrever a construção do ethos do voluntário como um herói e os estereótipos sobre a África apresentados no vídeo. A análise baseia-se nas noções de cena validada, ethos (MAINGUENEAU, 2006, 2010, 2015, 2020) e estereótipos (ALLPORT, 1979; AMOSSY; PIERROT, 2001; GATTI, 2014; BURKE, 2017). O video é uma produção do Norwegian Students' and Academics' International Assistance Fund (SAIH), uma agência humanitária internacional, politicamente independente, que promove o acesso à educação em diferentes paises. A agência critica o modo simplificado, redutor e muitas vezes pejorativo como a mídia ocidental, as organizações humanitárias e os discursos acadêmicos disseminam informações sobre a África. Para combater essas simplificações, a agência realiza campanhas problematizando esses estereótipos, como o vídeo analisado. Os resultados mostram que as campanhas estabelecem duas imagens: um ethos de um herói bom e bem-intencionado versus estereótipos de africanos como passivos, pobres e doentes.
\end{abstract}

Palavras-chave: Análise do Discurso. Ethos. Estereótipo. Cena validada. Discurso humanitário.

\begin{abstract}
This article analyzes the video "How to get more likes on Social Media" in order to describe the construction of the ethos of the volunteer as a hero and the stereotypes about Africa presented in the video. The analysis is based on the notions of ethos, scene validated (MAINGUENEAU, 2006, 2010, 2015, 2020), and stereotypes (ALLPORT, 1979; AMOSSY; PIERROT, 2001; GATTI, 2014; BURKE, 2017). The video was produced by the Norwegian Students' and Academics' International Assistance Fund (SAIH), a politically independent international humanitarian agency that promotes access to education in different countries. The agency criticizes the simplified, reductive, and often pejorative way in which Western media, humanitarian organizations, and academic discourses disseminate information about Africa. Against these simplifications, the agency carries out campaigns that problematize these stereotypes, as the video analyzed. The results show that the campaign establishes two images: an ethos of a good and well-meaning hero versus stereotypes of Africans as passive, poor, and sick.
\end{abstract}

Keywords: Discourse Analysis. Ethos. Stereotype. Validated scene. Humanitarian discourse.

\section{Introdução}

Noerwgian Students' and Academics' Internacional Assistance Fund (doravante SAIH) é uma agência humanitária internacional, politicamente independente, formada por estudantes e acadêmicos, buscando

\section{(c) (i)}

Artigo está licenciado sob forma de uma licença Creative Commons Atribuição 4.0 Internacional. 
promover o acesso à educação em diferentes países. O que chama a atenção para esse fundo de assistência é a sua posição crítica em relação ao modo simplificado como a mídia ocidental, as organizações humanitárias e a academia divulgam informações sobre a África e os países em desenvolvimento. O SAIH critica o fato de as campanhas das organizações humanitárias mostrarem apenas guerras, pobreza e conflitos.

De acordo com a organização, essas imagens simplificadas têm sido obstáculos para o desenvolvimento efetivo dos lugares representados, dado que as campanhas humanitárias acabam sendo contraproducentes, pois não mostram, por exemplo, as verdadeiras causas da pobreza. Nessas campanhas, os moradores locais são representados como passivos e sem o desejo de desenvolver seu país, enquanto os voluntários são retratados como heróis. Desse modo, cria-se uma representação oposta entre um voluntário ativo versus um nativo passivo e acomodado.

Com o intuito de combater essas simplificações, foi criado o projeto "Radi-Aid", o qual realiza campanhas que problematizam as representações da África e dos países em desenvolvimento veiculadas pelas agências humanitárias ocidentais. Uma dessas campanhas teve o propósito de orientar os jovens voluntários sobre as fotos tiradas durante as viagens humanitárias. Muitas destas são postadas nas redes sociais como meio de ganhar likes e reforçam estereótipos negativos sobre a África. Um dos materiais dessa campanha foi o video intitulado "How to get more likes on Social Media" ("Como conseguir mais likes nas mídias sociais").

Tendo isso em vista, o objetivo deste artigo é analisar discursivamente o vídeo citado, a fim de discutir a construção do ethos do voluntário herói e dos estereótipos sobre a África em campanhas de agências humanitárias. Para tanto, o presente artigo fundamenta-se nas noções de ethos, cena de enunciação, cena validada de Maingueneau (2006, 2010, 2015, 2020), bem como na noção de estereótipos, discutida por Allport (1979), Amossy e Pierrot (2001) e Burke (2017).

$\mathrm{O}$ artigo organiza-se do seguinte modo: primeiramente, apresenta a fundamentação teórica que embasa a pesquisa. A seguir, descreve as condições de produção de estereótipos sobre a África e a composição do vídeo. Em seguida, analisa o vídeo a partir das noções apresentadas.

\section{Cena de enunciação, ethos, estereótipos e cena validada}

Na perspectiva da Análise do Discurso (AD), Dominique Maingueneau (2010, p. 205) defende que todo texto é um rastro de discurso, "no qual a fala é encenada". Para a análise dos textos, ele propõe a noção de cena de enunciação, que é formada por três planos complementares: a cena englobante, a cena genérica e a cenografia.

A cena englobante refere-se ao tipo de discurso, "que resulta do recorte de um setor da atividade social caracterizável por uma rede de gêneros de discurso" (MAINGUENEAU, 2015, p. 118). A cena genérica, por sua vez, corresponde ao nivel imediato do gênero do discurso, "as cenas genéricas funcionam como normas que suscitam expectativas" (MAINGUENEAU, 2015, p. 120). Assim, cada cena genérica tem uma finalidade, papéis atribuidos aos parceiros, um lugar apropriado para seu sucesso, um modo de inscrição na temporalidade, um suporte, uma composição e um uso especíico dos recursos linguísticos. Por fim, a cenografia é construida pelo próprio texto e corresponde à encenação singular da enunciação. Conforme o autor:

A noção de cenografia se apoia na ideia de que
o enunciador, por meio da enunciação, organiza
a situação a partir da qual pretende enunciar.
Todo discurso, por seu próprio desenvolvi-
mento, pretende, de fato, suscitar a adesão
dos destinatários instaurando a cenografia
que o legitima (MAINGUENEAU, 2015, p. 123).

O autor estabelece que há uma escala entre as cenas genéricas que impõem sempre uma mesma cenografia, tal qual é o caso de uma receita médica, e as que permitem cenografias variadas, tal como é o caso da publicidade.

Maingueneau $(2006,2020)$ propõe que a noção de ethos participa da cena de enunciação, pois se manifesta nas três cenas. Além disso, de acordo com o autor, o ethos e a cenografia 
estão em um processo de enlaçamento: "desde sua emergência, a fala é carregada de um certo ethos, que, de fato, se valida progressivamente por meio da própria enunciação" (MAINGUENEAU, 2006, p. 68).

O autor retoma a noção de ethos desenvolvida por Aristóteles na Retórica. De acordo com o filósofo grego, o ethos forma uma triade com as noções de logos e pathos. Para ele, o ethos não é uma noção prévia sobre o orador, mas um efeito do seu discurso. A esse respeito, Maingueneau (2020, p. 11) explica que "a eficácia do ethos assemelha-se assim ao fato de ele envolver, de alguma maneira, a enunciação sem estar explicitado no enunciado. O ethos do qual falamos aqui é, portanto, um ethos propriamente discursivo". Assim, o ethos, na Retórica, não diz respeito a um saber extradiscursivo e estável sobre o enunciador, mas é construído no discurso, sendo um efeito percebido pelos coenunciadores.

Maingueneau (2020) propõe que, no âmbito da $A D$, há três tipos de ethos: o mostrado no ato de enunciação, o dito no enunciado e ainda o ethos pré-discursivo. O ethos dito não é obrigatório, enquanto mostrado é "uma dimensão constitutiva de toda a enunciação" (MAINGUENEAU, 2020, p. 12). Por sua vez, o ethos pré-discursivo é uma representação prévia que o destinatário tem do locutor antes mesmo de ele enunciar. A esse respeito, o autor salienta que "o simples fato de um texto resultar de um tipo, de um gênero de discurso e de determinado posicionamento ideológico induz expectativas em termos de ethos" (MAINGUENEAU, 2020, p. 12).

De acordo com Maingueneau (2020), o ethos diz respeito à representação avaliada que o destinatário constrói do locutor por meio daquilo que ele diz e de sua maneira para dizê-lo. Essa imagem do orador não é estática, mas dinâmica, porque é construida "por meio do próprio movimento da fala do locutor" (MAINGUENEAU, 2020, p. 10), e mobiliza tanto aspectos linguísticos, como a seleção vocabular, quanto paralinguísticos, como o tom de voz, o ritmo de fala, como ainda não verbais, tais como os gestos, a postura e as indumentárias. Conforme resume o autor, o ethos efetivo de um enunciador é resultado, portanto, "da interação entre seu ethos pré-discursivo, seu ethos discursivo (ethos mostrado), os fragmentos de textos no qual ele evoca sua própria personalidade (ethos dito)" (MAINGUENEAU, 2020, p. 12).

Maingueneau (2006, p. 56) ainda afirma que a questão do ethos está relacionada à construção da identidade: "cada tomada da palavra implica ao mesmo tempo levar em conta representações que os parceiros fazem um do outro, e a estratégia de fala de um locutor que orienta o discurso de forma a sugerir através dele uma certa identidade". Assim, em AD, a noção de ethos ultrapassa a problemática da argumentação, visto que não é pensado apenas como uma estratégia de persuasão, mas "permite refletir sobre o processo mais geral da adesão dos sujeitos a um certo posicionamento" (MAINGUENEAU, 2006, p. 61, grifo do autor), isto é, sobre o processo de incorporação. Nessa perspectiva, o autor propõe que mesmo os textos escritos têm uma vocalidade, que permite relacioná-los a uma corporalidade do enunciador: "a um 'fiador' que, por meio de seu 'tom', atesta o que é dito" (MAINGUENEAU, 2006, p. 61). A esse fiador são atribuidos um caráter, isto é, um feixe de traços psicológicos, e uma corporalidade, a saber, um comportamento, uma compleição física e maneira de se vestir e mover-se no espaço social. De acordo com o autor, esse fiador do discurso mobiliza um mundo ético de estereótipos culturais específicos.

A noção de estereótipo foi proposta na década de 1920, por Walter Lippmann. Na década de 1950, Gordon Allport publicou o livro The nature of prejudice (A natureza do preconceito), em que defende que os estereótipos são formados por uma generalização redutora, que muitas vezes pode ser pejorativa. De acordo com o Allport (1979), a categorização é um processo comum de funcionamento da mente humana, que possibilita a capacidade de julgamentos práticos sobre o mundo, uma vez que permite analisar os elementos em grupo e não um a um. Ou seja, a mente humana pensa a partir de categorias, que, uma vez formadas, permitem identificar rapidamente os objetos relacionados e realizar um 
prejulgamento essencial para dinâmica das ações cotidianas. Ao longo da vida, essas categorias são ajustadas e reagrupadas. $O$ autor ressalta que a mente humana tende a categorizar do modo mais fácil e, muitas vezes, o mais grosseiro possivel. Além disso, a essas categorias é atribuido um significado emocional (positivo ou negativo).

Allport (1979) defende que nem toda generalização é preconceituosa e que, às vezes, podem ocorrer alguns equivocos na organização das informações. Entretanto, conforme explica o autor, quando o prejulgamento não é mudado, mesmo quando é exposto um novo conhecimento sobre aquele objeto, individuo ou grupo, estamos diante de um caso de preconceito. Geralmente, quando há um preconceito, há muita resistência para mudá-lo. Além disso, o preconceito suscita sentimentos como o desprezo, a antipatia e o medo.

Conforme propõe Allport (1979), os estereótipos étnicos preconceituosos são constituidos por hostilidade e rejeição, atribuindo a um indivíduo ou a um grupo as supostas caracteristicas desagradáveis. Assim, o estereótipo étnico preconceituoso é baseado em uma generalização inadequada a respeito de um grupo ou de um individuo desse grupo. Esse preconceito pode ser apenas sentido ou expresso. Para explicar as manifestações dos preconceitos, o autor elabora uma escala de niveis de ações preconceituosas: o primeiro deles é a antilocução, nivel em que as pessoas preconceituosas falam entre si sobre os grupos que são discriminados. O segundo é o nivel da esquiva do contato com o grupo que é discriminado. O terceiro é a discriminação. Mais ativo que o anterior, nesse nivel, a pessoa preconceituosa se compromete em excluir certos grupos de direitos básicos, como o acesso a certos tipos de emprego, bairros, oportunidades de educação e lazer. É, portanto, o nível da segregação de certos grupos. O quarto nivel é o dos ataques físicos de violência. E, por fim, o quinto nivel é o da exterminação de um grupo étnico. $O$ autor ressalta que se pode ir de um nivel a outro de modo muito rápido.

Também tratando sobre os estereótipos, o historiador Peter Burke (2017) defende que o encontro entre diferentes culturas é normalmente marcado pela construção de estereótipos do outro, sendo um dos modos de construção desses estereótipos um jogo de oposição, que produz do outro uma forma invertida da própria autoimagem.

Amossy e Pierrot (2001) inscrevem a noção de estereótipo na perspectiva da AD, aproximando-a da noção de pré-construído de Pêcheux, aquilo que é dito em outro lugar e independentemente. As autoras afirmam que os estereótipos étnicos preconceituosos servem, muitas vezes, como um instrumento de legitimação, em que a produção da imagem negativa do outro funciona como uma forma de subordiná-lo.

Sobre os estereótipos, Gatti (2014) adverte que uma das diferenças entre essa noção e a dos pré-construidos é que estes são da ordem do linguistico, enquanto aqueles podem ser percebidos em outras semioses, tal qual é o caso das imagens e dos vídeos. A respeito das imagens, recorremos à noção de cena validada de Maingueneau (2006). De acordo com o autor, as cenas validadas são cenas "já instaladas na memória coletiva, seja a titulo de algo que se rejeita ou de modelo valorizado" (MAINGUENEAU, 2006, p.122123). Para ele, os mais diversos públicos têm um estoque de cenas validadas, que são apoiadas em estereótipos.

Tendo isso em vista, defendemos nesta pesquisa que os estereótipos negativos funcionam na memória discursiva no sentido de reforçar discursos preconceituosos. Sobre a memória discursiva, Courtine e Marandin (2016) afirmam que os discursos são constituídos em uma rede de repetições. Nas palavras dos autores, os discursos são constituídos:

[...] como um processo de repetições mais ou menos regulado - polimorfo nos discursos cotidianos, ritualizado nos discursos do aparelho - em que as palavras se tomam na rede das reformulações: repetição no modo do reconhecimento de enunciados e no modo do desconhecimento do interdiscurso (COURTINE; MARANDIN, 2016, p. 51).

A partir desse referencial, procederemos à análise do vídeo. Para tanto, apresentamos, na seção a seguir, aspectos da construção dos estereótipos sobre a África a partir de uma visão 
eurocêntrica do mundo.

\section{0 eurocentrismo e os estereótipos sobre a África}

Visentini (2014) defende que o fim da Guerra Fria promoveu certa marginalização do continente africano frente ao sistema internacional, dado que perdeu sua importância estratégica no conflito entre Leste-Oeste. Nesse período, o continente passou a enfrentar vários conflitos internos, consoante explica o autor:

Com armas menos modernas, financiamento das máfias e senhores da droga (cujo cultivo se expandia rapidamente em muitas regiões do continente) e intromissão de potências médias locais e externas, estes conflitos persistiram até como forma de sobrevivência de elites e populações nas áreas mais afetadas. Alguns acordos de paz, como os de Angola, não foram respeitados, com a persistência da guerra e a devastação de amplas regiões (VISENTINI, 2014, p. 148).

Além disso, o continente passou a enfrentar uma grave crise sanitária:

A globalização e o fim da Guerra Fria desarticularam interna e externamente a politica africana, gerando conflitos "desestrategizados" em meio ao alastramento da pobreza, da megaurbanização caótica e do ressurgimento de doenças epidêmicas como a cólera. O HIV/Aids fez avanços notáveis, especialmente na África Austral e Centro-oriental, o cólera ressurgiu com força e novas epidemias letais, como a do virus Ebola, surgiram na África Central em meio à deterioração das condições sociais e sanitárias (VISENTINI, 2014, p. 149).

Entretanto, cabe destacar que houve também, nesse periodo, profundas alterações geopolíticas no continente com o crescimento dos regimes democráticos:

Regimes de partido único eram substituidos, frente a pressões internas e externas, por sistemas liberal-democráticos multipartidários; Estados em guerra civil como Angola (maio de 1991) e Moçambique (outubro de 1992) assinavam acordos de paz e os demais regimes marxistas eram derrubados, como na Etiópia, em maio de 1991. A própria África do Sul anunciou, em fevereiro do mesmo ano, o fim do Apartheid, após a libertação do líder negro Nelson Mandela no ano anterior (VISENTINI, 2014, p. 147)
Desse modo, no período, o continente africano enfrentava uma série de epidemias, conflitos identitários e também de mudanças políticas. Enquanto a atenção da mídia mundial era para a globalização crescente, marcada pela abertura do Leste Europeu e pela expansão da União Europeia, quando se tratava do continente africano, as notícias se concentravam sempre em aspectos de miséria, produzindo, assim, cada vez mais um discurso afropessimista. Visentini (2014) explica que os conflitos na África muitas vezes são noticiados pela imprensa de forma caricatural, sem considerar os aspectos sociais, culturais, políticos e econômicos, inclusive de interesse internacional, que provocaram e mantêm esses conflitos. A mídia internacional, muitas vezes, não identifica os atores tanto domésticos quanto estrangeiros que produzem esses conflitos, assim como não discute os padrões de intervenção (primeiramente, europeia e, mais recentemente, norte-americana) a que o continente tem sido submetido. Portanto, embora a história recente África seja marcada por relações complexas, muitas vezes esse continente tem sido representado de forma redutora e simplista por um estereótipo que o associa apenas à pobreza e à miséria.

Nesse contexto, diversas agências humanitárias, com propósito variados, têm agido no sentido de promover ajuda para os conflitos. Algumas delas são bem conhecidas como os Médicos sem Fronteiras, a Cruz Vermelha e Fundo das Nações Unidas para a Infância (UNICEF), que realizam ações de longo prazo em regiões carentes. Para tanto, essas agências promovem campanhas publicitárias a fim de arrecadar fundos para o trabalho voluntário. De um modo geral, essas campanhas, que se fundamentam na evidência de que a pobreza deve ser combatida, constituem-se na representação de um "eles" carentes e necessitados que demandam a atuação de um "nós" heroico e salvador. No caso da África, historicamente, esse continente tem sido representado por um discurso ocidental-cristão como carente de ajuda. Para tratar dessa questão, mobilizamos o conceito de eurocentrismo, conforme explicam Shohat e Stam (2006, p. 21, grifo dos autores): 
O eurocentrismo bifurca o mundo em "Ocidente e o resto" e organiza a linguagem do dia a dia em hierarquias binárias que implicitamente favorecem a Europa: nossas nações, as tribos deles; nossa arte, o artesanato deles; nossas manifestações, os tumultos deles; nossa defesa, o terrorismo deles.

Assim, essa visão bipartida estabelece duas posições: um nós versus um outro (eles). Conforme explica Burke (2017, p. 184), "nessa ótica, seres humanos como nós são vistos como 'outros'". Desse modo, constrói-se uma autoimagem positiva como herói, em contraposição a uma imagem negativa do outro, como atrasado e necessitado de ajuda, produzindo um estereótipo étnico preconceituoso. Seguindo essa lógica, a África tem sido representada, portanto, a partir de um discurso eurocêntrico como um continente atrasado, doente e pobre.

Shohat e Stam (2006, p. 20) ainda propõem que o eurocentrismo é uma

[...] tentativa de reduzir a diversidade cultural a apenas uma perspectiva paradigmática que vê a Europa como a origem única dos significados, como o centro de gravidade no mundo, como "realidade" ontológica em comparação com a sombra do resto do planeta. O pensamento eurocêntrico atribui ao "Ocidente" um sentido quase providencial de destino.

Nesse sentido providencial, os europeus seriam responsáveis por converter o restante do mundo aos princípios tidos por eles como civilizados. Essa posição sustenta os vários processos de colonização seja da África, seja das Américas, seja das várias regiões do Oriente Médio e da Ásia. Os europeus atribuiram a si a responsabilidade de civilizar o mundo, adotando como critérios de comparação as regras estabelecidas por eles. No Brasil, por exemplo, todo o processo de colonização baseou-se no critério da imposição das regras portuguesas aos indigenas e, mais tarde, aos africanos trazidos para o país. Houve, por exemplo, a imposição da religião católica, sendo as demais classificadas de modo negativo como práticas demoniacas. A figura do missionário no discurso católico lembra a do voluntário: aquele que atende à demanda de uma população. 0 discurso humanitário inscreve-se nessa memória de que há um outro que demanda por ajuda, pois está em uma situação de calamidade, de pobreza, de necessidade, de não civilização. Essa perspectiva, construida com base no eurocentrismo, funciona como justificativa para o colonialismo, o imperialismo e o discurso racista, produzindo efeitos nos discursos sobre o continente africano.

Convém destacar também o papel estadunidense hoje nas intervenções humanitárias: embora os Estados Unidos não sejam propriamente eurocêntricos - ainda que, pelo processo de colonização por povoamento, haja uma ideia de continuidade entre ingleses e norte-americanos -, são etnocêntricos que se apresentam, muitas vezes, como responsáveis por manter a paz no mundo.

Tendo isso em vista, propomos que é preciso pensar na profusão de imagens da África na chamada sociedade ocidental. Há uma recorrência de imagens, de cenas validadas, no sentido de Maingueneau (2006), que sustentam estereótipos que ligam a África à pobreza e à doença. Uma cena recorrente são as imagens de crianças africanas muito magras, sujas e pobres. Esta é uma cena validada nas campanhas das agências humanitárias, em que os africanos são retratados como pobres, carentes e, muitas vezes, violentos, em contrapartida a um ethos do europeu/estadunidense como um agente civilizador bondoso. Desse modo, essas campanhas promovem um apagamento de vários processos históricos pelos quais esses povos passaram graças à política europeia e também norte-americana de dominação e exploração do mundo.

Cabe salientar ainda que, na sociedade ocidental, a preocupação com a pobreza tem um valor positivo. Para os jovens mais abastados, por exemplo, as viagens de cunho humanitário têm funcionado como uma espécie de rito de iniciação para o autoconhecimento e um sinal de bom caráter. Assim, paralelamente às agências humanitárias, têm surgido, cada vez mais, agências de viagem especializadas em turismo humanitário, como a The International Ecotourism Society e a Volunteer Vacations, que vendem experiências personalizadas de fazer diferença 
no mundo. O público-alvo dessas agências são os jovens de classe alta e média alta.

Uma reportagem, intitulada "Voluntarismo: o risco do turismo de voluntariado que movimenta milhões", de autoria de Martín Caparrós e publicada pelo portal El País em 20 de dezembro de 2018, chama a atenção para a prática do voluntarismo, que tem movimentado milhões de pessoas e de dólares. Esse tipo de viagem tem uma curta duração, de duas ou três semanas, em que o voluntário deve praticar alguma ação caridosa, como trabalhar em um orfanato ou ajudar na construção de uma casa popular. No entanto, algumas questões problemáticas têm chamado a atenção. Por exemplo, como se mostra na reportagem, há indícios de que, no Camboja, houve um crescimento rápido do número de orfanatos, sendo que dois terços dos órfãos que vivem nesses lugares não são realmente órfãos, mas crianças de familias carentes que atuam oferecendo aos voluntários a experiência de cuidar dos órfãos. Outra questão é que a enorme quantidade de dinheiro gasta com a experiência não é necessariamente direcionada aos necessitados. Por exemplo: o custo para a construção de uma casa popular em Honduras é de cerca de 2 mil dólares, porém a mesma casa construida na ação voluntária chega a custar 30 mil dólares, quando somadas todas as despesas da viagem. Por fim, a reportagem destaca que o voluntarismo serve, muitas vezes, como um incremento para o currículo dos jovens, abrindo-lhe portas de emprego, tendo em vista que a caridade é um valor positivo na sociedade ocidental.

A partir dessas considerações acerca dos estereótipos sobre a África e a prática do turismo humanitário, passamos à descrição e à análise do vídeo.

\section{Descrição do vídeo}

Com o intuito de combater as simplificações estereotipadas sobre a África, o SAlH criou o projeto "Radi-Aid", que realiza campanhas problematizando tais representações do continente. Entre os materiais criados, está o vídeo intitulado "How to get more likes on Social Media", que orienta os jovens voluntários sobre as fotos tiradas durante as viagens humanitárias. O video citado, com a duração de um minuto e vinte e sete segundos, está disponivel no canal do SAIH no YouTube e já tem mais de 300 mil visualizações. O vídeo é uma animação que narra a história de uma jovem em busca de aumentar o número de likes em suas fotos nas redes sociais. Para ajudá-la, ao longo do vídeo, são apresentadas instruções, em letras grandes e rosas, sobre como conseguir mais curtidas. Desse modo, o vídeo tem também um caráter de manual, como o próprio nome aponta.

O primeiro cenário do vídeo mostra a jovem branca, em sua casa, olhando fotos que têm mais de 10 mil likes nas redes sociais. Em uma delas, por exemplo, aparece um jovem branco, sem camisa, forte e bronzeado, equilibrando algumas crianças negras em seus braços e cintura (Figura 1). A foto é acompanhada da legenda "Real heroes don't wear capes" ("Verdadeiros heróis não utilizam capas") e das hashtags \#brolife e \#savetheworld. Em contrapartida, a jovem visualiza a sua foto sozinha, em casa, que teve apenas três likes (Figura 2).

Figura 1 - Jovem voluntário equilibrando crianças nos músculos

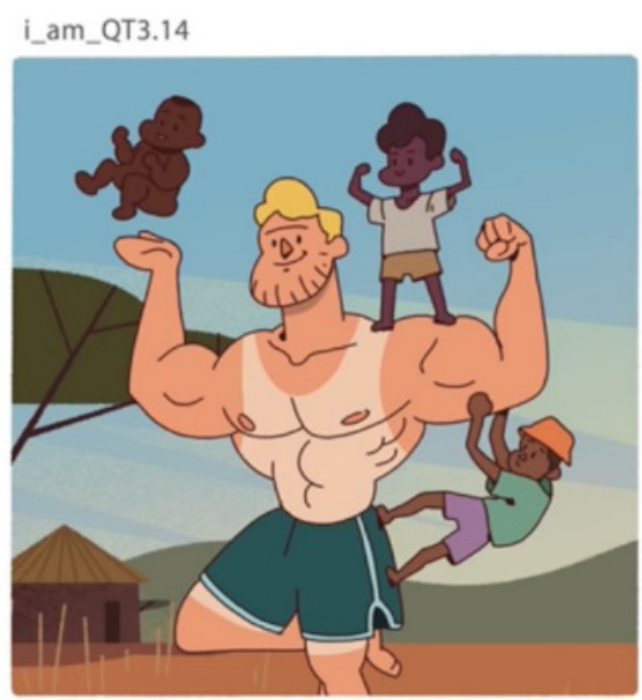

11971

Real heroes don't wear capes \#brolife \#savetheworld

Fonte: SAIH Norway (2017). 
Figura 2 - Selfie em casa

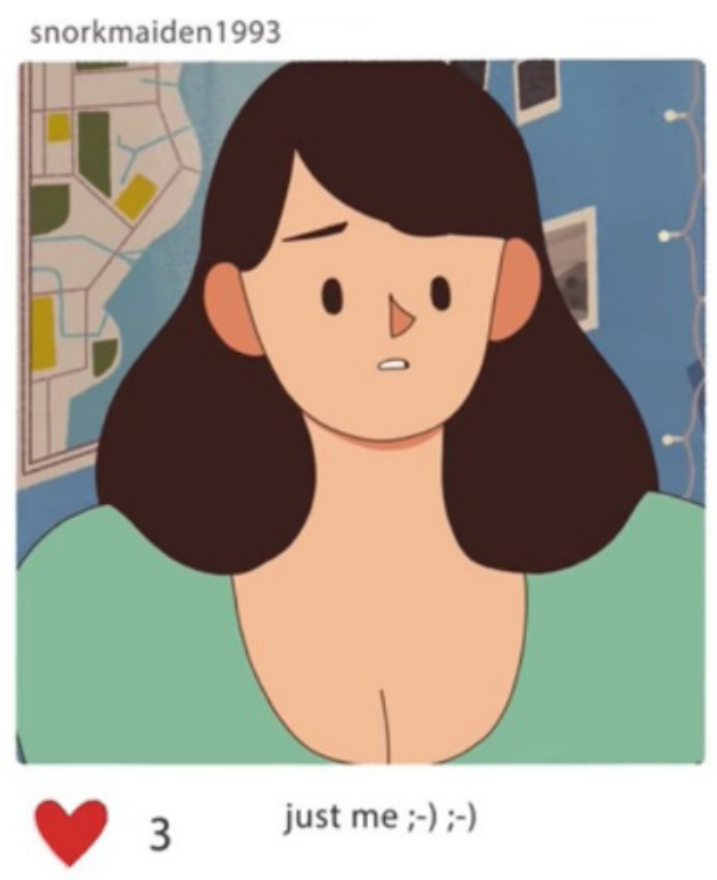

Fonte: SAIH Norway (2017).

Indignada, a jovem decide aumentar seu número de likes viajando para o continente africano. Nesse momento, aparece a primeira instrução do vídeo: "Viaje para a África". Ao chegar lá, a protagonista vê um menino negro, sem camisa, dormindo embaixo de uma árvore, algumas moscas sobrevoam a cabeça dele. Nesse momento, ouve-se o barulho típico de uma câmera fotográfica e aparece na tela a indicação para aumentar o número de likes: "Foque o que importa". Entretanto, a cena seguinte rompe com o esperado ao mostrar que ela não está tirando uma foto do garoto, mas sim uma selfie de seu próprio rosto, fazendo um biquinho. Postada, com a legenda "finalmente na África", a selfie alcança 500 likes.

Figura 3 - Selfie na África

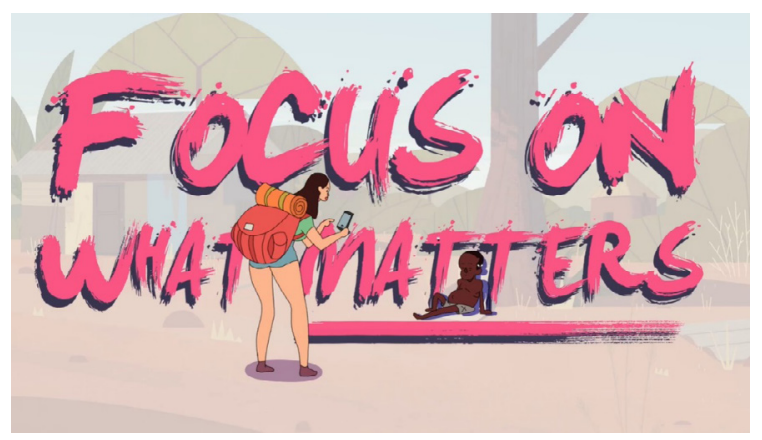

Fonte: SAIH Norway (2017).
A seguir, ela faz outra selfie segurando um chocolate e, ao fundo, o menino debaixo da árvore agora está acordado e com uma expressão de assustado ao ver a jovem. A foto é postada com a legenda "my brave Angels" ("Meus anjos corajosos"), hashtags: \#FeedAfrica e \#PoorAfrica.

O próximo cenário é uma escola. Nesse momento, aparece a seguinte instrução: "Crianças = Likes". Assim, a protagonista faz uma selfie com três crianças segurando barras de chocolate. A foto é acompanhada da legenda "My African children" ("Minhas crianças africanas") e das hashtags: \#FeedAfrica e \#PoorAfrica. Essa foto alcança 1320 likes. Ainda na escola, a protagonista aparece na frente da turma, juntamente com um professor negro, que tem uma expressão de preocupação com a atuação dela. Ela escreve no quadro em uma aula de Matemática: "Classe de dietas de poucos carboidratos". A seguir, conforme mostra a Figura 4, a protagonista posta uma foto do próprio traseiro, enquanto está abaixada ajudando uma criança a escrever. A legenda da foto é "What's more important than squats? Knowlegde!" ("O que é mais importante que agachamentos? Conhecimento!"), acompanhada das hashtags: \#sharing, \#booksmarts. A foto alcança 5560 likes.

Figura 4 - Foto na escola

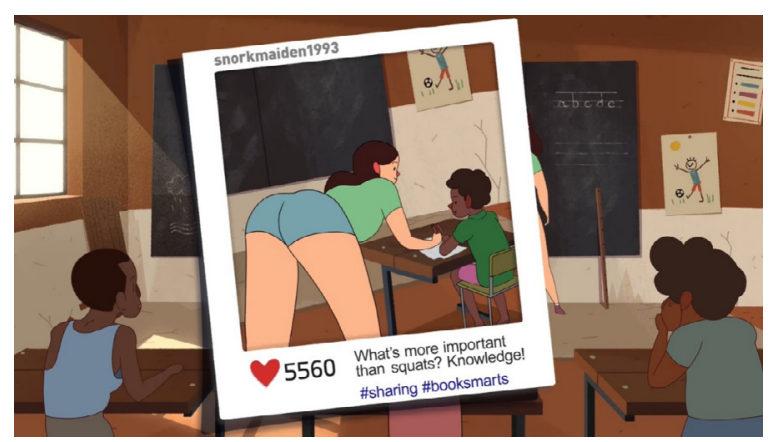

Fonte: SAIH Norway (2017).

O último cenário é o de um hospital, onde a jovem faz uma selfie, com semblante triste, ao lado de uma criança deitada em uma cama, e utiliza a seguinte legenda: "just doing my part" ("Apenas fazendo a minha parte") e a hashtag \#heartbreaking. A selfie alcança 9859 likes, conforme mostra a Figura 5. A seguir, aparece mais uma instrução no vídeo "Suffering will give you 
twice the likes" ("Sofrimento vai lhe dar o dobro de likes"). Enquanto a garota tira selfies, os profissionais de saúde aparecem incomodados com a presença dela, como indica a Figura 6, em que o médico está impaciente olhando o relógio.

Figura 5 - Selfie no hospital

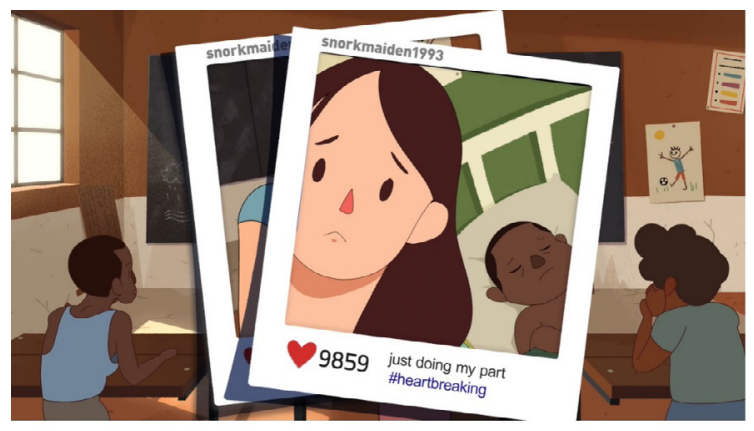

Fonte: SAIH Norway (2017).

Figura 6 - Profissionais da saúde observando a jovem voluntária no hospital

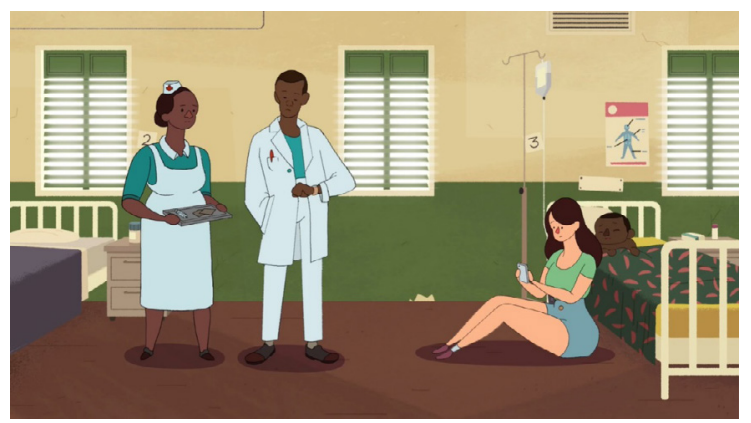

Fonte: SAIH Norway (2017).

A última indicação do vídeo, em letras rosas, é "Always remember hashtags" ("Sempre se lembre das hashtags"). Por fim, aparecem uma faixa preta, que indica interdição, com a indicação \#nostereotypes. "Stereotypes harm dignity" ("Estereótipos ferem a dignidade"), e os slogans do projeto Radi-aid e do SAIH.

\section{Análise do vídeo}

Em termos de cena de enunciação, a cena englobante é o discurso humanitário e a cena genérica é de um manual. A finalidade do vídeo é alertar sobre o modo como jovens têm exibido suas viagens humanitárias à África como um meio de ganhar notoriedade nas redes sociais. Marquez e Ardévol (2018) explicam que o YouTube, lançado em 2005, é o segundo maior buscador da internet, depois do Google, e tem sido um espaço privilegiado para o lançamento e a difusão dos mais variados conteúdos, tornando-se, ao lado de outras redes sociais, um espaço digital onipresente na vida cotidiana, principalmente dos mais jovens. Nesse espaço, surge a figura do youtuber que disponibiliza em seu canal vídeos. Os youtubers têm ganhado cada vez mais popularidade e atraem não só público, mas também patrocínio para seus canais. Marquez e Ardévol (2018) ressaltam o papel dos youtubers no consumo midiático dos jovens, bem como o papel deles nos processos de aprendizagem desse público. Um gênero típico dos vídeos do YouTube são os manuais que ensinam uma diversidade de tarefas. Assim, em termos de cena genérica, o lugar apropriado para o sucesso do vídeo em análise é estar disponibilizado no YouTube, como um manual que ensina a ganhar likes. O manual em vídeo inscreve-se, portanto, em uma temporalidade atual de sucesso das redes sociais, em que estar conectado e ter muitas curtidas nas fotos são fatores positivos e índices de popularidade.

$\mathrm{O}$ video, produzido pelo $\mathrm{SAIH}$, dirige-se aos jovens que participam do turismo humanitário. No vídeo, apela-se para a figura do voluntário como um herói. O ethos do herói é construido por um fiador de caráter bondoso, generoso e atencioso, que se dispõe a viajar para ajudar, e de corporalidade atlética, conforme aparece na Figura 1, que mostra a imagem de um jovem voluntário exibindo seus músculos. Há, assim, a mobilização de um mundo ético de uma juventude bem-intencionada, generosa e altruísta, ao mesmo tempo que é atlética, trabalhadora e ativa. Essa representação tem um valor positivo na sociedade ocidental. Essa figura funciona como um lugar de desejo para os jovens que querem alcançar esse status, que rende, entre outros benefícios, popularidade nas redes sociais. Em contraposição, evoca-se uma memória sobre o continente africano, como pobre e carente, reforçando estereótipos dos africanos como passivos e necessitados de ajuda, conforme pode ser exemplificado na Figura 3, em que aparece a 
representação de uma criança africana dormindo calmamente, mesmo diante do dito cenário de necessidade. Nesse contexto, a figura do voluntário surge como o herói que vai ajudar a resolver os problemas da África.

Passamos agora para a análise da cenografia do vídeo. Nele, é encenada a vida de uma jovem que viaja como voluntária para África, mas tem como meta ganhar popularidade nas redes sociais. No video, são dadas as seguintes instruções: Viaje para a África; Foque o que importa; Crianças = Likes; Sofrimento vai the dar o dobro de likes; Sempre se lembre das hashtags. Maingueneau (2020, p. 22) afirma que, "quando estudamos o ethos, precisamos identificar estereótipos linguisticos, maneiras de falar tipificadas que, se espera, destinatários pertencentes a determinada comunidade vão reconhecer e avaliar". No video, as instruções dadas recorrem ao modo de falar típico dos usuários das redes sociais que valorizam o recebimento de likes e entendem o funcionamento das hashtags.

As duas primeiras instruções evocam o papel esperado do voluntário: alguém que despretensiosamente busca ajudar e aliviar o sofrimento, ou seja, alguém que é bondoso e altruista. Assim, ao fazer essas ações, o voluntário constrói uma imagem positiva de si, como engajado, prestativo e bom. Destarte, era esperado que a voluntária tivesse como foco as crianças africanas, porém o que ela destaca é a própria imagem, por isso, sempre está tirando selfies. A terceira instrução aponta para o uso das crianças para a promoção pessoal, ao propor que as crianças atraem likes. A mesma posição é defendida na quarta instrução: o foco no sofrimento alheio produz o dobro de likes. Há nessas instruções uma posição de que fazer o bem tem um valor positivo na sociedade, rendendo likes.

A respeito da última instrução ("Sempre se lembre das hashtags), a hashtag é uma palavra-chave antecedida pelo simbolo cerquilha (\#), que cria um hiperlink para a publicação, indexando-a a fim de que possa ser encontrada em pesquisas. A escolha de uma hashtag não é aleatória. Bruns e Burgess (2011) explicam que a hashtag é um mecanismo que permite comunicar-se com uma comunidade de interesse, mesmo sem estabelecer uma relação de seguir/seguidores. No video, as postagens são acompanhadas de várias hashtags, relacionadas a diferentes temas. Por exemplo, \#brolife é uma hashtag que evoca um estilo de vida jovem, produzindo um ethos mostrado jovem, de caráter corajoso e corporalidade aventureira e atlética. Por sua vez, as hashtags \#savetheworld, \#feedAfrica e \#poorAfrica estão relacionadas ao domínio do discurso humanitário. A primeira constitui-se na evidência de que o mundo deve ser salvo, permitindo o questionamento: salvo do quê? Na relação estabelecida com a imagem, retoma-se um discurso sobre a salvação da África, materializado nas duas últimas hashtags (\#feedAfrica e \#poorAfrica), que retomam estereótipos negativos sobre esse continente, como lugar de pobreza e fome. Sendo assim, o voluntário é convidado a resolver tais problemas, produzindo um ethos mostrado heroico, de caráter bondoso e corporalidade prestativa e engajada. Chamamos ainda a atenção para a hashtag \#sharing (\#compartilhando), que funciona com um sentido duplo, por um lado, \#sharing remete ao discurso humanitário de compartilhar, isto é, doar tempo, objetos, serviços, dinheiro; por outro lado, remete ao mundo das midias sociais de compartilhar imagens e posts.

Por último, ao final do vídeo, aparece a interdição "Estereótipos ferem a dignidade", que muda o script de leitura do vídeo, que não deve ser interpretado como um manual do que deve ser feito, mas, sim, do que deve ser evitado. Assim, o video problematiza a representação típica da África, a partir de estereótipos preconceituosos, comum nas campanhas humanitárias. Desse modo, as instruções dadas são uma critica ao modo como as crianças africanas e o seu sofrimento têm sido explorados nessas campanhas. Por exemplo, a jovem dá chocolates às crianças em uma atitude simplista para reduzir a fome, que não contribui efetivamente para os casos de desnutrição infantil.

No cenário da escola, ao escrever no quadro "Aula sobre a baixa ingestão de carboidratos", 
retoma-se uma memória sobre a África como um lugar de fome, em que a população de muitos paises sofre com a desnutrição e a alta mortalidade infantil. No vídeo, essa memória é contraposta a outra em que a baixa ingestão de carboidratos diz respeito à realização de dietas para manter a forma, aliada a exercícios fisicos, conforme indica a imagem de valorização do traseiro da jovem (Figura 4). Destarte, o papel da voluntária na escola é criticado uma vez que ela não apenas está mais preocupada consigo mesma (postando fotos do próprio corpo), como compara a baixa ingestão de alimentos por causa de fatores socioeconômicos à realização de dietas, por vontade própria, para manter a forma, tratando da questão da fome e da desnutrição de forma simplista, o que indica o seu desconhecimento sobre as reais causas e efeitos da pobreza. Além disso, há uma crítica à atuação da jovem no hospital. Os profissionais de saúde que estão efetivamente trabalhando no local estão incomodados com a presença dela, um deles, inclusive, olha para o relógio e resmunga, em atitude de impaciência, como indica a Figura 6. Assim, questiona-se se esse trabalho voluntário, não especializado, realmente promove alguma mudança efetiva na vida dos doentes.

Analisamos, também, o ethos do SAlH, agência criadora do vídeo. O fiador do vídeo tem um papel moral de questionamento sobre a real eficácia da ajuda dada. Com um caráter severo, problematiza não apenas o papel dos jovens turistas na ação humanitária, como também a própria ação das agências humanitárias que, ao longo da história, têm colaborado para perpetuar uma caracterização estereotipada e negativa sobre continente africano, com campanhas que recorrem sempre ao mesmo lugar comum da pobreza e da miséria. Há ainda um ethos didático, em que o destinatário é posto em uma situação de aprendizagem sobre não apenas o modo de comportamento em uma viagem humanitária, mas sobre a própria representação típica do continente africano. Para tanto, no vídeo, recorre-se à cenografia típica apresentada nas campanhas das agências humanitárias, as quais apelam, de um modo geral, para cenas validadas típicas: crianças pobres e famintas, escolas simples e hospitais improvisados, a fim de problematizar essas representações. Há, portanto, uma quebra de expectativa de um ethos pré-discursivo que os destinatários têm desse gênero de vídeo.

Por fim, chamamos a atenção para a primeira instrução: Viaje para a África. No vídeo, é indicado que a jovem vai para a África de um modo geral, porém não se especifica uma cidade ou um país, logo o efeito de sentido é que em qualquer parte do continente se encontram pessoas carentes e necessitadas de ajuda. Vieira (2006) elenca que um dos estereótipos mais comuns sobre a África é a ideia de unidade do continente, como tendo uma única identidade, uma única história e, muitas vezes, até mesmo sendo representado apenas como um país, ignorando e reduzindo, portanto, toda a diversidade étnica, cultural, linguistica e sociopolítica do continente.

\section{Considerações finais}

A análise mostra que o vídeo problematiza o modo como as campanhas das agências humanitárias têm representado o continente africano a partir de estereótipos étnicos preconceituosos. Retomando Allport (1979), podemos afirmar que a construção dessas campanhas está no primeiro nivel das ações preconceituosas: a antilocução, quando se fala mal do outro a partir de uma posição preconceituosa. Assim, ao produzirem de si (dos voluntários) um ethos heroico, de caráter bondoso e corporalidade ativa e atlética, as campanhas produzem também, paralelamente e em contraposição, a representação dos africanos como acomodados, passivos e necessitados. Há, portanto, como propõe Burke (2017), a construção de estereótipos a partir de uma forma invertida da autoimagem. Ademais, esse primeiro nivel de ação preconceituosa permite outros niveis, como a discriminação contra os povos africanos. Em consonância com que explicam Amossy e Pierrot (2001), esses estereótipos que desvalorizam contribuem para a subordinação dos grupos étnicos.

Além disso, o vídeo problematiza a ideia de que todos podem ser voluntários, na medida em que a jovem se mostra não apenas despreparada, 
mas também inconveniente, interrompendo uma aula para falar de um assunto que ela não domina, bem como interrompendo o tratamento de um paciente apenas para tirar uma selfie. Há ainda a problematização da ideia de que a África precisa dos voluntários, rompendo com o estereótipo de uma África passiva e dependente. Tanto na escola quanto no hospital, o video mostra que há profissionais habilitados trabalhando que são interrompidos pela jovem.

Por fim, a análise permitiu refletir sobre a cena de enunciação típica das campanhas humanitárias, que recorrem a cenografias baseadas em estereótipos sobre o continente africano. Essas campanhas têm veiculado, a partir de cenas validadas do discurso humanitário, a imagem de crianças pobres e carentes, em contraposição à imagem do voluntário como herói. Essas representações são fundamentadas em uma visão eurocentrada do mundo, dividida entre um nós e um eles, que contribui para o reforço de uma memória sobre a África como carente e passiva, silenciando as ações dos diversos agentes externos que exploram o continente e têm interesse que essa imagem estereotipada persista.

\section{Referências}

ALLPORT, Gordon Willard. The nature of prejudice. Nova York: Basic Books, 1979.

AMOSSY, Ruth; PIERROT, Anne Herschberg. Estereotipos y clichés. Buenos Aires: Eudeba, 2001.

BRUNS, Axel; BURGESS, Jean. The use of Twitter hashtags in the formation of ad hoc publics. In: THE EUROPEAN CONSORTIUM FOR POLITICAL RESEARCH (ECPR), 2011, Reykjavik. Proceedings of l.... Reino Unido: ECPR, 2011. p. 1-9.

BURKE, Peter. Testemunha ocular: o uso de imagens como evidência histórica. São Paulo: Ed. UNESP, 2017.

CAPARRÓS, Martín. Voluntarismo: o risco do turismo de voluntariado que movimenta milhões. El País, 20 dez. 2018. Disponivel em: https://brasil.elpais.com/ brasil/2018/12/11/eps/1544541087_701313.html. Acesso em: 17 dez. 2020.

COURTINE, Jean-Jacques; MARANDIN, Jean-Marie. Que objeto para a Análise do Discurso? In: CONEIN, Bernard et al. Materialidades discursivas. Campinas: Ed. UNICAMP, 2016. p. 33-54.

GATTI, Márcio Antônio. Estereótipo e pré-construido: é possivel uma articulação? Revista Signótica, [S. L.], v. 26. n. 2, p. 397-414, 2014
MAINGUENEAU, Dominique. Cenas da enunciação. Curitiba: Criar, 2006.

MAINGUENEAU, Dominique. Discurso e Análise do Discurso. São Paulo: Parábola, 2015

MAINGUENEAU, Dominique. Doze conceitos em Análise do Discurso. São Paulo: Parábola, 2010

MAINGUENEAU, Dominique. Variações sobre o ethos São Paulo: Parábola, 2020

MARQUEZ, Israel; ARDEVOL, Elisenda. Hegemonia y contrahegemonía en el fenómeno youtuber. Desacatos, México, n. 56, p. 34-49, abr. 2018.

HOW TO GET more likes on Social Media. Animaskin [S. l.], 2017. 1 video ((1min 27seg). Publicado pelo canal SAIH Norway. Disponivel em: https://Www.youtube. com/watch?v=7c9 mwY31iMl. Acesso em: 8 ago. 2020.

SHOHAT, Ella; STAM, Robert. Critica da imagem eurocêntrica: multiculturalismo e representação. São Paulo: Cosac Naify, 2006.

VIEIRA, Francisco Sandro Silveira. Do eurocentrismo ao afropessimismo: reflexão sobre a construção do imaginário da "África" no Brasil. Em Debate: Revista do Departamento de Serviço Social PUC-Rio, Rio de Janeiro, n. 3, p. 1-15, 2006.

VISENTINI, Paulo Fagundes. Da marginalização ao "renascimento africano". In: VISENTINI, Paulo Fagundes; RIBEIRO, Luiz Dario Teixeira; PEREIRA, Analúcia Danilevicz (org.). História da África e dos africanos. 3. ed. Petrópolis: Vozes, 2014. p. 145-187.

\section{Daiane Rodrigues de Oliveira Bitencourt}

Doutora em Linguistica pela Universidade Estadual de Campinas (Unicamp), em Campinas, SP, Brasil. Especialização (em andamento) em História e Cultura Afro-brasileira e Indígena pelo Centro Internacional (Uninter), em Campinas, SP, Brasil. Membro do grupo de pesquisa Fórmulas e Estereótipos - Teoria e Análise (FEsTA), IEL/Unicamp.

\section{Endereço para correspondência}

\section{Daiane Rodrigues de Oliveira Bitencourt}

Universidade Estadual de Campinas Instituto de Estudos da Linguagem

R. Sérgio Buarque de Holanda, 571, Bloco VII, sala 2.04A Cidade Universitária, 13083-859

Campinas, SP, Brasil

Os textos deste artigo foram revisados pela Poá Comunicação e submetidos para validação da autora antes da publicação. 